\title{
Novel use of a self-expanding metal stent for an esophageal stricture after radiofrequency ablation treatment of Barrett's esophagus
}
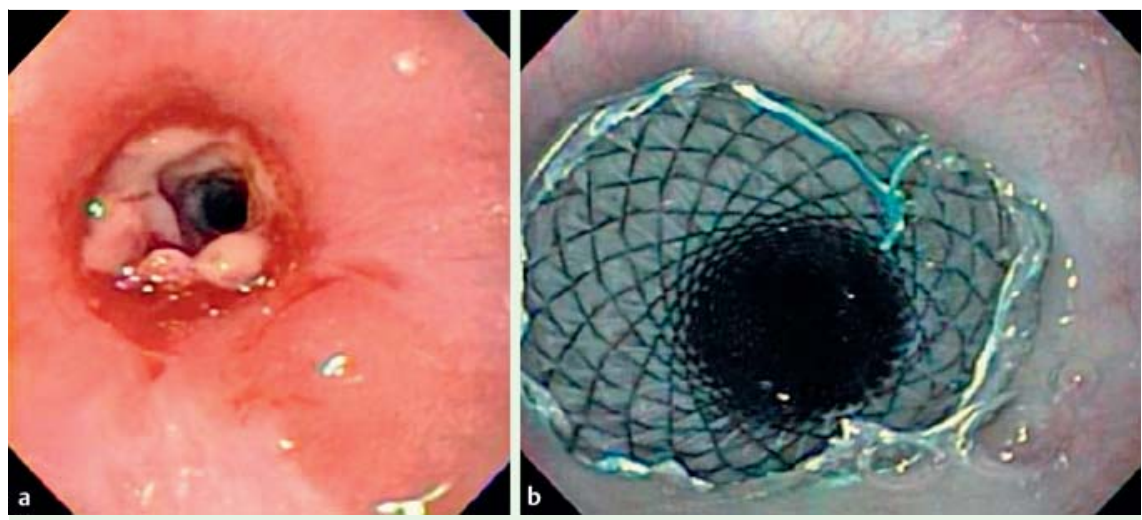

Fig. 1 Endoscopic images showing: a a tight stricture with circumferential ulceration at the proximal end of the area of Barrett's epithelium that had been treated by radiofrequency ablation (RFA); $\mathbf{b}$ a fully covered metal esophageal stent deployed in the esophagus.

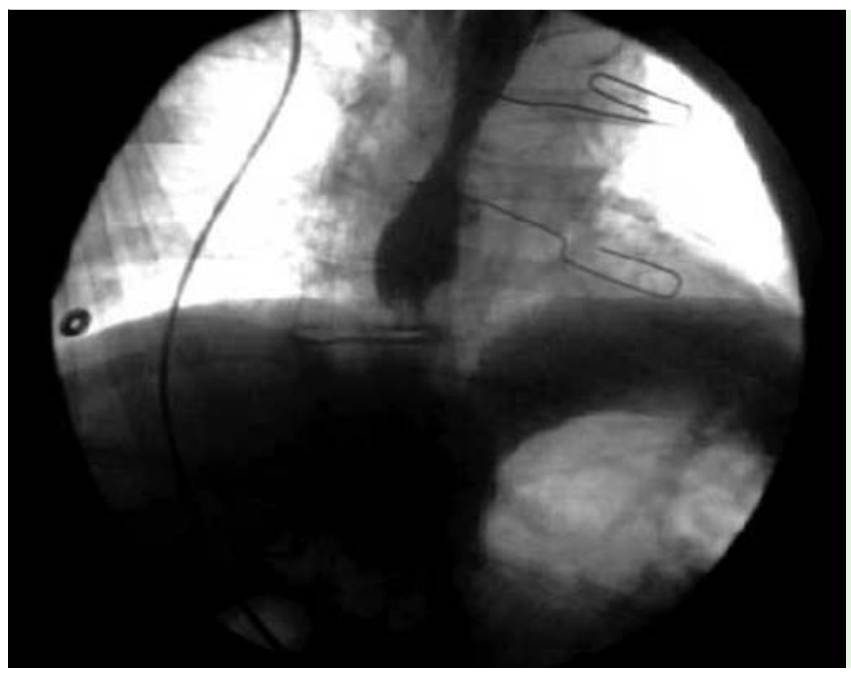

Fig. 2 Radiographic image following injection of contrast showing a waist in the midportion of the stent, with free flow of contrast into the stomach.

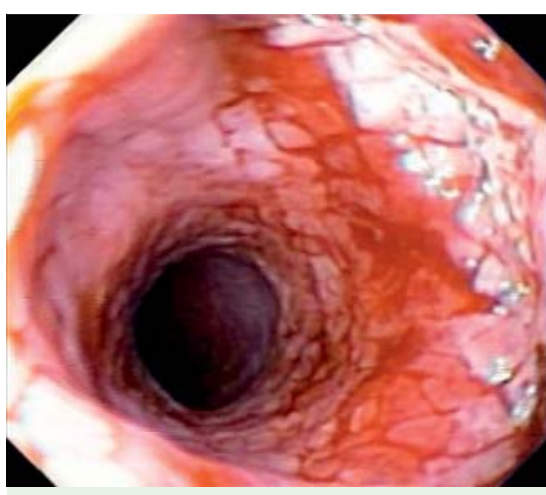

Fig. 3 Endoscopic view of the esophagus following removal of the stent 2 months later.

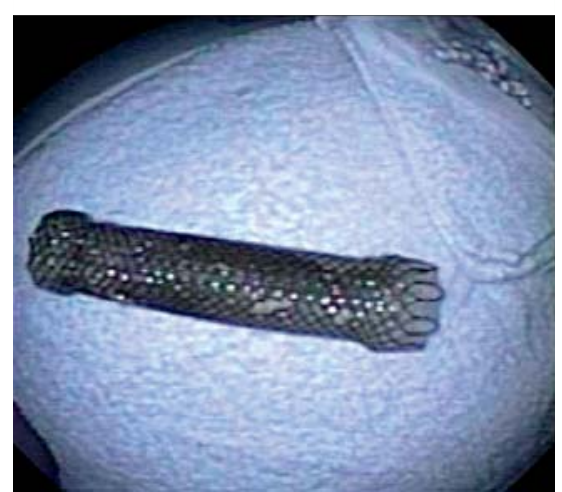

Fig. 4 The fully covered, $23 \times 105-\mathrm{mm}$, esophageal self-expanding metal stent (SEMS).

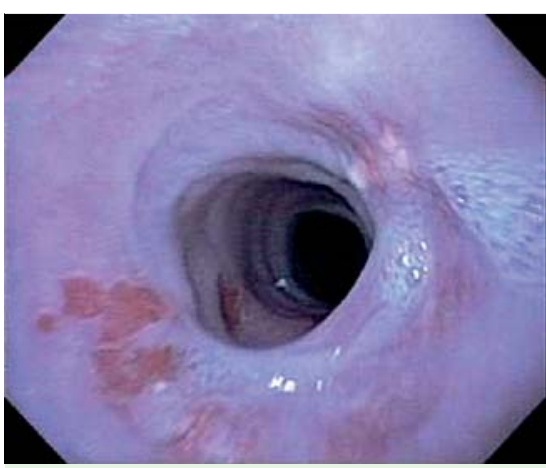

Fig. 5 Endoscopic appearance 6 months later showing a well-healed fibrotic stricture.

Radiofrequency ablation (RFA) is effective and safe in the treatment of Barrett's esophagus [1]. The incidence of esophageal stricture after RFA treatment is reported to be up to $8 \%$ [2]. Stricture rates may be increased with RFA of long-segment Barrett's esophagus. Strictures are treated endoscopically with balloons or Savary dilators; however, there is a risk of perforation with these treatments. We report on the successful treatment of a patient with a stricture following RFA using a self-expanding metal stent (SEMS).

A 71-year old man with long-segment Barrett's esophagus (C7M7) and lowgrade dysplasia underwent circumferential RFA. A month later he reported dysphagia and odynophagia, and endoscopy revealed a tight stricture with circumferential ulceration at the proximal end of the RFA-treated area of Barrett's epithelium ( $\bullet$ Fig. 1 a).

A gastroscope with a 5.9-mm diameter was advanced to the proximal end of the stricture; however, the distal end of the stricture could not be traversed. A gastroscope with an $8.8-\mathrm{mm}$ diameter was therefore inserted and a 9-12-mm extraction balloon (Extractor Pro RX; Boston Scientific, Natick, Massachusetts, USA) was introduced. Injection of contrast revealed a $4-5 \mathrm{~cm}$ long stricture in the mid-esophagus. A stent introducer was passed over a 450-cm, 0.035-inch guidewire (Dreamwire; Boston Scientific), which had been passed through the stricture under fluoroscopic guidance. A fully covered metal esophageal stent $(23 \times 105 \mathrm{~mm}$, 
WallFlex; Boston Scientific) was deployed ( $\bullet$ Fig. 1 b). A further attempt to pass the $5.9 \mathrm{~mm}$ gastroscope through the stricture was unsuccessful. The extraction balloon was reintroduced and injection of contrast showed a waist in the mid-portion of the stent, but with free flow of contrast into the stomach ( $\bullet$ Fig. 2 ).

The stent was removed 2 months later ( Fig. 3 and $\bullet$ Fig. 4 ) and after 6 months, the patient had no symptoms of dysphagia and was found to have a well-healed fibrotic stricture on endoscopy ( $\bullet$ Fig.5). To our knowledge, this is the first case of an esophageal stricture occurring after RFA that was successfully treated by placement of a fully covered removable metal stent. Use of a self-expandable metal stent has also been reported for a stricture occurring after photodynamic therapy for Barrett's esophagus [3]. Treatment of tight strictures with metal stents may be a cost-effective treatment as it avoids the need for repeated dilations and the possible subsequent complications [4].
Endoscopy_UCTN_Code_CPL_1AH_2AJ

Competing interests: None

\section{Traci Murakami, Bhaskar Banerjee, Nuri Ozden}

Division of Gastroenterology, Hepatology and Nutrition, University of Arizona

Medical Center, Tucson, Arizona, USA

\section{References}

1 Shaheen $N$, Sharma P, Overholt B et al. Radiofrequency ablation in Barrett's esophagus with dysplasia. N Engl J Med 2009; 360: 2277-2288

2 Garman K, Shaheen N. Ablative therapies for Barrett's esophagus. Curr Gastroenterol Rep 2011; 13: 226-239

3 Cheon YK. Metal stenting to resolve postphotodynamic therapy stricture in early esophageal cancer. World J Gastroenterol 2011; 17: 1379-1382

4 Van Halsema E, Wong Kee Song L, Baron T et al. Safety of endoscopic removal of self-expandable stents after treatment of benign esophageal diseases. Gastrointest Endosc 2013; 77: $18-28$
Bibliography

DoI http://dx.doi.org/

10.1055/s-0034-1365428

Endoscopy 2014; 46: E269-E270

(c) Georg Thieme Verlag KG

Stuttgart · New York

ISSN 0013-726X

Corresponding authors

Nuri Ozden, MD

1501 N. Campbell Avenue PO Box 245028

Tucson

AZ 85721

USA

Fax: +1-520-874-7133

nozden1@gmai.com

Traci Murakami, MD

1501 N. Campbell Avenue PO Box 245028

Tucson

AZ 85721

USA

traci.murakami@gmail.com 